University of Nebraska - Lincoln

DigitalCommons@University of Nebraska - Lincoln

USDA National Wildlife Research Center - Staff Publications
U.S. Department of Agriculture: Animal and Plant Health Inspection Service

2008

Nicarbazin bait reduces reproduction by pigeons (Columba livia)

Michael L. Avery

USDA/APHIS/WS National Wildlife Research Center, michael.I.avery@aphis.usda.gov

Kandy L. Keacher

USDA/APHIS/WS National Wildlife Research Center

Eric A. Tillman

USDA/APHIS/WS National Wildlife Research Center, eric.a.tillmann@aphis.usda.gov

Follow this and additional works at: https://digitalcommons.unl.edu/icwdm_usdanwrc

Part of the Environmental Sciences Commons

Avery, Michael L.; Keacher, Kandy L.; and Tillman, Eric A., "Nicarbazin bait reduces reproduction by pigeons (Columba livia)" (2008). USDA National Wildlife Research Center - Staff Publications. 993. https://digitalcommons.unl.edu/icwdm_usdanwrc/993

This Article is brought to you for free and open access by the U.S. Department of Agriculture: Animal and Plant Health Inspection Service at DigitalCommons@University of Nebraska - Lincoln. It has been accepted for inclusion in USDA National Wildlife Research Center - Staff Publications by an authorized administrator of DigitalCommons@University of Nebraska - Lincoln. 


\title{
Nicarbazin bait reduces reproduction by pigeons (Columba livia)
}

\author{
Michael L. Avery A,B, Kandy L. Keacher ${ }^{\mathrm{A}}$ and Eric A. Tillman ${ }^{\mathrm{A}}$ \\ AUSDA-APHIS National Wildlife Research Center, Florida Field Station, 2820 East University Avenue, \\ Gainesville, FL 32641, USA. \\ ${ }^{B}$ Corresponding author. Email: michael.I.avery@aphis.usda.gov
}

\begin{abstract}
Development of effective methods for reducing populations of overabundant nuisance bird species continues to challenge wildlife biologists. Reproductive inhibition, although conceptually pleasing, has been difficult to implement because of the lack of a safe, approved avian contraceptive. Recently, however, nicarbazin received regulatory approval in the United States for use as a bait to decrease hatchability of resident Canada goose (Branta canadensis) and feral pigeon (Columba livia) eggs. In anticipation of the feral pigeon registration, we evaluated efficacy by exposing captive pairs of nesting pigeons to nicarbazin bait for $4 \mathrm{~h}$ daily. Egg production was unaffected, but only 9 of 22 eggs hatched, a $59 \%$ reduction from pre-treatment when each of the 11 test pairs produced 2 nestlings. In the recovery phase, when treated bait was removed, the 11 pairs produced 18 nestlings. All nestlings produced during the study appeared healthy and normal, and there was no mortality among the adult pairs. Nicarbazin is an effective and safe means of reducing hatchability of feral pigeon eggs that can be used within an integrated management plan to reduce feral pigeon populations.
\end{abstract}

\section{Introduction}

In the United States, the feral pigeon (Columba livia) is an invasive nuisance species responsible for estimated damages of more than US\$1 billion annually (Pimentel et al. 2000). At least 70 human pathogens have been identified as being harboured in feral pigeon populations (Haag-Wackernagel 2006). Although numerous methods for managing pigeon populations have been contrived and marketed, the species continues to thrive in urban and rural settings (Johnston 1992; Johnston and Janiga 1995). Thus from the perspectives of property damage, aesthetics, human health and safety, and animal husbandry, there are ample reasons for development of effective alternative management options to lower the population level of this invasive species.

Population regulation through fertility control is potentially most effective for wildlife species characterised by high rates of reproduction (Dolbeer 1998). Such species generally exhibit an early age of first breeding, a relatively short lifespan, multiple clutches or litters annually, and a limited period of parental care. The feral pigeon is a good example of such a species. Individuals are sexually mature before they are 1 year old, the average lifespan is 2.4 years, they can produce 5 or 6 broods annually, and young birds depart the nest as early as 25 days of age (Johnston 1992).

One option for management of feral pigeons recently approved for use in the USA is OvoContol P (Innolytics LLC, Rancho Santa Fe, CA; USEPA registration no. 80224-1), a reproductive inhibitor with $5000 \mathrm{ppm}$ nicarbazin $(\mathrm{NCZ})$ as the active ingredient. NCZ is an equimolar complex consisting of 4,4'-dinitrocarbanilide (DNC) and 2-hydroxy-4,6-dimethylpyrimidine (HDP). It has been used as a coccidiostat in broiler chicken feeds since the 1950s (Jones et al. 1990). NCZ also reduces egg production and hatchability by compromising the integrity of the egg's vitelline membrane, allowing yolk and albumen to mix (Sherwood et al. 1956; Yoder et al. 2006a). The chemosterilant effect of NCZ is temporary, and birds recover fully 4-6 days after being taken off treated food (Yoder et al. 2005).

The capacity for NCZ to reduce hatchability was previously exploited in the development of NCZ bait for managing resident Canada goose (Branta canadensis) populations (Yoder et al. 2005, 2006b; Bynum et al. 2007). Furthermore, a NCZ-based product (Ovistop, Acme Drugs, Italy) has been used to reduce urban pigeon populations in Italy for several years, purportedly with good results (www.ovistop.it). Recent careful review of the Italian experience, however, raised concerns about the effectiveness of Ovistop and more generally about the usefulness of reproductive inhibition as a population-management tool for feral pigeons (Giunchi et al. 2007).

In Italy, Ovistop is usually applied to maize for pigeon control, but Giunchi et al. (2007) report that this bait does not appeal to pigeons. Giunchi et al. (2007) fed a pelleted bait made from bird seed to captive pigeons, but acceptance of pellets relative to the maize bait is difficult to determine as their methodology differed between trials. Moreover, Giunchi et al. (2007) present no data on actual food consumption, and they report no information on blood chemistry to assess absorption of NCZ by the birds.

Because bait formulation is critical to successful delivery of a chemosterilant to target birds, we conducted a series of preliminary trials with captive pigeons to assess bait consumption and to document uptake of NCZ by test birds (Avery et al. 2006). These trials identified a pelleted bait containing 5000 ppm NCZ that was readily accepted and that produced desired levels of NCZ in blood plasma of female birds.

In anticipation of its being registered for use in the US, we tested the candidate 5000-ppm NCZ bait formulation (OvoContol P) to verify its efficacy for managing feral pigeon 
populations. In particular, our objectives were to: (1) document effects of NCZ bait consumption on egg and chick production in pairs of captive pigeons; (2) relate plasma NCZ levels in hen birds to levels in eggs; and (3) assess recovery of captive pigeons from exposure to NCZ bait.

\section{Methods}

\section{Study design}

We employed a quasiexperimental before-after design, a type that is used extensively in psychology, pharmacology, medicine, environmental analysis, and other fields of study (Smith 2002; Harris et al. 2005). Inclusion of an untreated control group would have strengthened our design. Doing so would also have added 22 adult birds and 60 nestlings to the study, each of which would have been killed. Instead, we opted against the unnecessary use of animals (Russell and Burch 1959). The study consisted of three phases: pretreatment, treatment, and recovery. The pretreatment phase established the baseline productivity for each pair. The treatment phase served to evaluate the responses of each pair to exposure to the treated bait (OvoControl P). The recovery phase documented productivity of test pairs once they were removed from the treatment.

\section{Test subjects}

We selected 11 pairs of pigeons from those available in the captive population at our field station in Gainesville, Florida. Six of the female birds had been obtained from trappers in the Gainesville area, and five others (1 Janssen strain, 4 Huyskens-van Riels) had been procured from local pigeon breeders (Table 1). For testing we used pairs that had previously proven to be reliable egg-producers, without regard for the sources of the birds.

At least 2 weeks before the start of the study, we placed each pair of birds in a $1.2 \times 1.8 \times 1.2-\mathrm{m}$ cage in a roofed outdoor aviary. Each cage included a plastic milk crate as a nesting platform, a food bowl, and a water dish. Inside each milk crate we provided a ceramic dish $25 \mathrm{~cm}$ in diameter with $5.5-\mathrm{cm}$-high sides, and we placed pine straw and twigs inside each dish for the birds to use as nesting material. The nest-dish facilitated inspections of the nest contents and prevented eggs from rolling out of the nest. We inspected nests daily and also noted the general appearance and condition of the birds in each test cage.

When not exposed to treated bait, the birds had unlimited access to their usual maintenance diet, a 10:1:1 mixture of quail starter (Hillandale Farms), commercial pigeon pellets (Purina NutriBlend Green), and cracked corn. Throughout the study, Kaytee high-calcium pigeon grit was provided ad libitum. Blood samples and unhatched eggs collected throughout the study were sent to the National Wildlife Research Center in $\mathrm{Ft}$ Collins, $\mathrm{CO}$, where concentrations of DNC were determined (Johnston et al. 2002). DNC is the bioactive constituent of NCZ and serves as a marker for assessing exposure to NCZ (Primus et al. 2001). All birds were killed with carbon dioxide at the end of the study (Andrews et al. 1993).

\section{Pretreatment}

The female in each pair was weighed and a blood sample was taken. Each pair of pigeons was allowed to produce a clutch of eggs and to incubate these eggs normally. After Day 10 of incubation, we offered each pair $40 \mathrm{~g}$ of the 5000-ppm nicarbazin test bait for $4 \mathrm{~h}$ daily (0800-1200 hours). During this 4-h period no other food was offered. We provided maintenance food again when treated food was removed. Provision of treated food at this time ensured sufficient opportunity for NCZ levels in the blood to be elevated when the females next ovulated. We measured consumption of treated food three times per week. Clutches were allowed to hatch, and when nestlings were 14 days old we examined them for abnormalities or deformations and weighed them to determine body mass (Bennett and Ganio 1991). We then killed the nestlings using carbon dioxide (Andrews et al. 1993).

\section{Treatment}

We continued to provide each pair of birds with a daily ration (40 g) of 5000-ppm NCZ-treated bait and provided new nesting material (small sticks, pine straw) to stimulate renesting. The bait is a hard, extruded wheat-based product. The cylindrically shaped particles are designed for ready consumption by pigeons (mean diameter $=3.31 \mathrm{~mm}$, s.e. $=0.04$; mean length $=4.59 \mathrm{~mm}$, s.e. $=0.19 ; n=20$ particles). We measured consumption of the treated test diet by each pair of birds three times per week.

Table 1. Characteristics and responses of nesting female pigeons exposed to nicarbazin-treated bait (5000 ppm)

Source: W, wild-caught; DH, captive, Huysken-van Riels strain; DJ, captive, Janssen strain. NCZ, nicarbazin; BM, body mass; DNC, 4,4'-dinitrocarbanilide

\begin{tabular}{lcccccc}
\hline Cage & Source & $\begin{array}{c}\text { Nestlings produced } \\
\text { Treatment }\end{array}$ & $\begin{array}{c}\text { Daily ingestion of } \\
\text { Recovery }\end{array}$ & $\begin{array}{c}\text { Body mass } \\
\left.\text { NCZg }(\mathrm{kg} \mathrm{BM})^{-1}\right)\end{array}$ & $\begin{array}{c}\text { Plasma DNC } \\
(\mathrm{g})\end{array}$ \\
\hline 204 & DH & 1 & 2 & 121.33 & 484.3 & 1.20 \\
206 & DJ & 0 & 1 & 132.35 & 464.7 & 3.63 \\
211 & W & 0 & 0 & 122.61 & 318.1 & 5.17 \\
213 & W & 1 & 2 & 83.84 & 354.1 & 0.10 \\
215 & W & 0 & 1 & 132.97 & 396.3 & 11.40 \\
223 & W & 1 & 2 & 113.51 & 385.4 & 8.18 \\
228 & DH & 1 & 2 & 88.06 & 463.7 & 8.78 \\
232 & DH & 2 & 2 & 79.55 & 407.4 & 3.73 \\
248 & W & 0 & 2 & 79.38 & 352.3 & 3.85 \\
256 & W & 1 & 2 & 93.66 & 343.8 & 8.72 \\
293 & DH & 2 & 2 & 83.71 & 490.3 & 3.95 \\
\hline
\end{tabular}


Presentation of treated food continued until either (a) the second clutch of eggs was laid or (b) 28 days elapsed from removal of the first set of nestlings. If no new egg was produced after 28 days, we assumed that none would be laid. In a previous study (Avery et al. 2006), nesting pairs of pigeons took 8-18 days ( $n=11$ pairs) from removal of their nestlings to initiation of their next clutch. Because we were not certain how the treated bait would affect the interval between clutches, we arbitrarily added 10 days to the previous maximum value to form the 28-day limit. When either condition (a) or (b) was met by a given pair of birds, we weighed the female bird and collected a blood sample. We stopped providing NCZ-treated food, and that pair henceforth received maintenance food only. One pair laid a clutch of eggs five days after cessation of presentation of treated food. We included that clutch as part of the treatment phase even though it occurred outside the nominal 28-day limit.

Pairs were allowed to incubate the second clutch normally. If by Day 23 of incubation, the eggs did not hatch, the eggs were collected and refrigerated for eventual NCZ analysis. Normally the incubation period is 18-19 days (Johnston 1992). We extended that to 23 days to provide a margin of safety to reduce the chance of our removing any clutch prematurely. If the eggs hatched, we examined the nestlings at 14 days of age for abnormalities or deformities and weighed and killed them.

\section{Recovery}

We allowed each pair of birds free access to maintenance diet, and we provided new nesting material (small sticks, pine straw) to stimulate renesting. When a new clutch was produced, we weighed the female bird and collected a blood sample. Incubation proceeded unimpeded. We examined nestlings at 14 days of age for abnormalities or deformities and we allowed the nestlings to develop normally.

\section{Consumption of treated food}

We weighed test food rations to $0.01 \mathrm{~g}$ on an electric balance calibrated annually by an authorised technician. We presented test food in 8-cm-diameter plastic cups within 25-cm-diameter plastic bowls to catch spillage. A cup containing test food not exposed to birds was put in a vacant cage to determine mass changes due to moisture. We weighed contents of the food cup and spill bowls at the end of the 4-h presentation period, and calculated consumption by subtraction after appropriate adjustments for spillage and moisture gain. Calculations of daily food consumption were rounded to the nearest $0.1 \mathrm{~g}$. For each pair, we estimated the mean daily exposure to NCZ based on the body mass of the birds, food consumption, and the treatment rate (5000 ppm).

\section{Data analyses}

We tested differences in the numbers of 14-day-old nestlings between pretreatment and treatment and between pretreatment and recovery periods using the Wilcoxon signed ranks test (Langley 1970). We used a one-tailed nonparametric test because the only possible response of each pair to the treatment was either no, one, or two nestlings. We tested the null hypothesis that the median did not differ from 0 , with the alternate hypothesis of the median $>0$ because during pretreatment each pair produced two nestlings, and a negative difference would require production of three nestlings, an extremely unlikely event. Rejection of the null hypothesis $(\alpha=0.05)$ signifies a reduction in productivity due to the NCZ treatment.

Using a paired $t$-test, we tested the null hypothesis that the interval from the end of the pretreatment stage to initiation of the treatment-stage clutch did not differ from the interval beginning at the end of the treatment stage to initiation of the recovery-stage clutch. We assessed levels of DNC in unhatched eggs relative to treated bait consumption and relative to DNC levels in the female bird using Pearson product moment correlation. When there were two eggs from the same female, we used the mean of the two DNC values for analysis.

\section{Results}

\section{Consumption of treated food}

Exposure to treated food ranged from 31 to 49 days depending on the time each pair took to lay its second clutch. Daily consumption of treated bait varied from 13.6 to $25.3 \mathrm{~g}$ per pair $($ mean $=17.7$, s.e. $=1.3)$. Body mass of wild-caught females $($ mean $=358.3 \mathrm{~g}$, s.e. $=11.6, n=6)$ was reduced $\left(F_{1,9}=31.65\right.$, $P<0.001)$ relative to those obtained from breeders (mean $=$ $462.1 \mathrm{~g}$, s.e. $=14.6, n=5$ ). Estimated daily intake of $\mathrm{NCZ}$ ranged from 79.6 to $133.0 \mathrm{mg} \mathrm{NCZ} \mathrm{(kg} \mathrm{body} \mathrm{mass)}{ }^{-1}$ (overall mean $=102.8$, s.e. $=6.6, n=11$ pairs $)$ and did not differ between sources of birds $\left(F_{1,9}=0.06, P=0.816\right)$.

\section{Nest productivity}

Each pair produced two viable eggs and two healthy chicks during the pretreatment phase. During the treatment phase, each pair again produced two eggs, and these resulted in a total of 10 hatchlings, one of which died within $24 \mathrm{~h}$. The total of nine viable 14-day-old offspring represents a 59\% reduction in number of nestlings produced relative to pretreatment $(P=0.005$; Wilcoxon test statistic $=45)$. Nine of 11 test pairs showed decreased productivity in response to the treatment. The mean estimated daily intake by two pairs that produced two nestlings each was $81.6 \mathrm{mg} \mathrm{NCZ}(\mathrm{kg} \text { body mass })^{-1}($ s.e. $=2.1)$, compared with $116.9 \mathrm{mg} \mathrm{NCZ}(\mathrm{kg} \text { body mass })^{-1}($ s.e. $=12.7)$ by the four pairs that produced no nestlings in the treatment phase (Fig. 1).

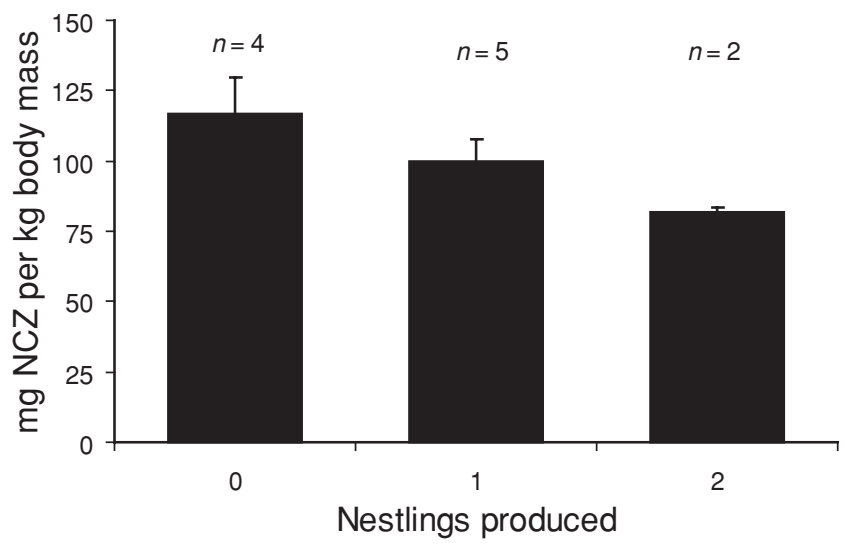

Fig. 1. Productivity of captive rock pigeons declined with increasing daily consumption of nicarbazin (NCZ). Capped vertical bars denote 1 s.e. 
In the recovery phase, 21 eggs and 18 chicks were produced, which did not differ from pretreatment $(P=0.09$; Wilcoxon test statistic $=6.0)$. Eight of nine pairs having reduced productivity during treatment increased production of young in the recovery phase. The interval between the end of the pretreatment phase and the initiation of the treatment phase clutch averaged 16.3 days (s.e. $=2.3, n=11$ ), compared with an 11.1-day mean interval (s.e. $=1.1, n=11$ ) from the end of the treatment phase to initiation of the recovery stage clutch $(t=3.24$, d.f. $=10$, $P=0.009)$.

\section{DNC in blood}

DNC was undetected in blood samples from the pretreatment phase. DNC in samples collected at the end of the treatment period ranged from $<1.0$ to $11.4 \mathrm{mg} \mathrm{kg}^{-1}$ (mean $=5.3$, s.e. $=$ 1.1). There was a tendency for nest productivity to decline as the DNC plasma level increased (Fig. 2), but small sample sizes and high variability resulted in no statistical relationship between plasma DNC levels in the hen birds and the number of nestlings produced $\left(F_{2,8}=0.22, P=0.809\right)$. DNC was detected in two pigeons during the recovery phase: $0.08 \mathrm{mg} \mathrm{kg}^{-1}$ and $0.11 \mathrm{mg} \mathrm{kg}^{-1}$, respectively. Each of these females produced two nestlings.

\section{DNC in eggs}

We submitted 14 unhatched eggs for DNC analysis. One egg broke in transit and was not analysed. Of the 13 remaining eggs, 11 were from the treatment phase of the study. Two contained embryos in advanced stages of development and were not analysed. The remaining nine eggs showed no evidence of embryo development, and there was a strong relationship ( $r=0.958$, $P=0.001, n=7$ ) between the pair's mean daily consumption of treated food and the DNC levels in eggs laid by the female (Fig. 3). Overall, the DNC levels in eggs were not correlated ( $r=0.323, P=0.480, n=7$ ) with the female's plasma DNC level. Excluding one outlying value, however, the DNC levels in eggs were correlated ( $r=0.909, P=0.012, n=6$ ) with DNC levels in the female pigeons that laid them (Fig. 4). Two unhatched eggs from the recovery phase had DNC levels of 0.08 and $0.94 \mathrm{mg} \mathrm{kg}^{-1}$, respectively.

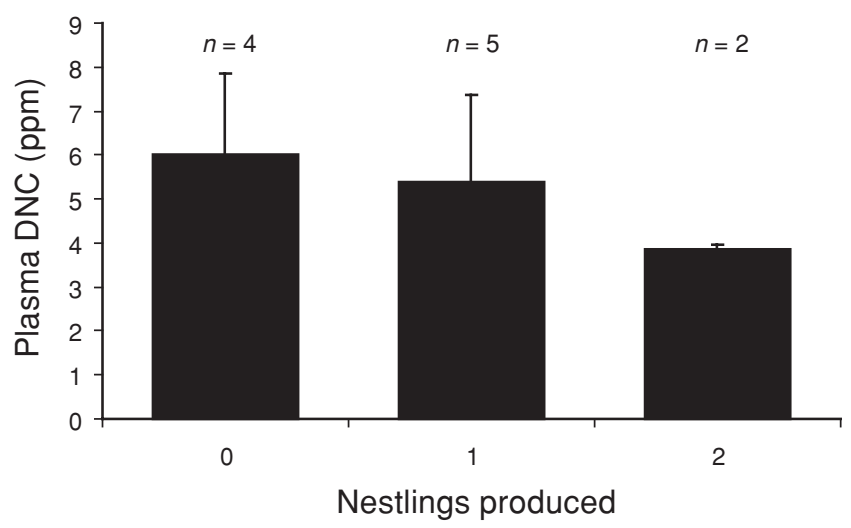

Fig. 2. Nestlings produced by captive female pigeons tended to decrease with increasing levels of plasma 4,4'-dinitrocarbanilide (DNC). Capped vertical bars denote 1 s.e.

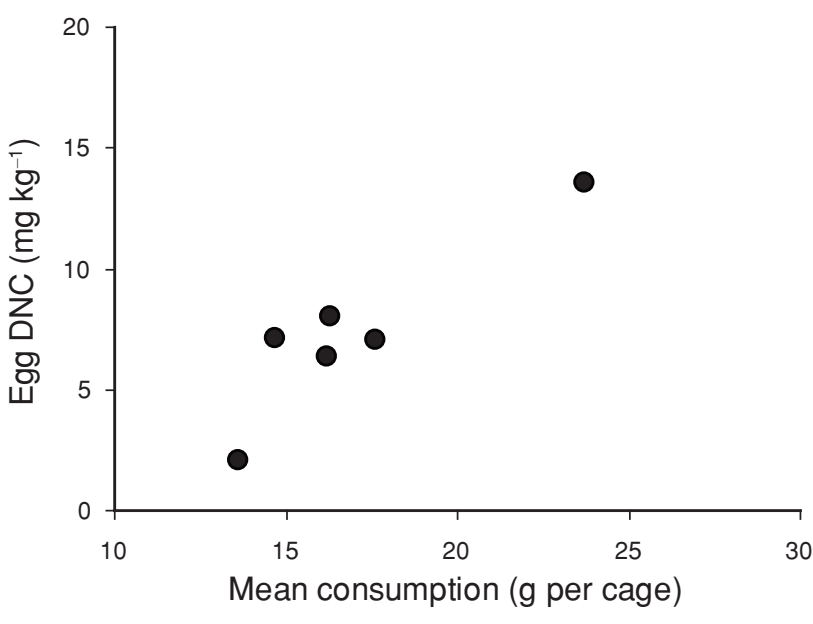

Fig. 3. Levels of 4,4'-dinitrocarbanilide (DNC) in unhatched pigeon eggs increased with mean daily consumption of nicarbazin-treated (5000 ppm) bait by the adult birds.

\section{Condition of nestlings}

With the exception of one treatment-phase nestling that died within $24 \mathrm{~h}$ of hatching, birds that hatched during the pretreatment and treatment phases of the study were killed when they were 14 days old. The mean body mass of 14-day-old nestlings from the pretreatment phase $(324.4 \mathrm{~g}$, s.e. $=8.6 \mathrm{~g}, n=22)$ was virtually the same as that in the treatment phase $(326.8 \mathrm{~g}$, s.e. $=16.4 \mathrm{~g}, n=8$ ). All 14-day-old nestlings appeared healthy with no obvious deformities or abnormalities.

\section{Discussion}

For effective reproductive control with nicarbazin, exposure to an appropriate dose is crucial. The effective dose will vary among species. An effective daily dose appears to be $30-40 \mathrm{mg}$ $\mathrm{NCZ}$ (kg body mass) $)^{-1}$ in waterfowl (Yoder et al. 2006b). In contrast, we found that a dose $\sim 3$ times as great was needed to

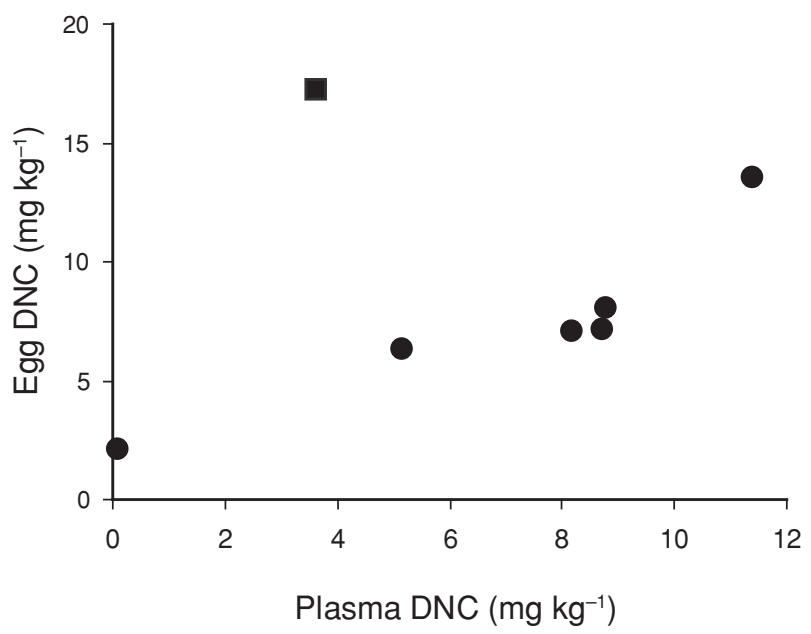

Fig. 4. 4,4'-Dinitrocarbanilide (DNC) levels in plasma of female pigeons and in unhatched eggs that they produced following daily exposure to nicarbazin-treated bait $(5000 \mathrm{ppm})$. Outlying point is indicated by a square. 
inhibit reproduction in captive pigeons (Fig. 1). Given appropriate exposure to $\mathrm{NCZ}$, production of nestlings decreased $59 \%$, and it then returned to normal after treatment stopped. We documented that the plasma DNC levels in the female pigeons were closely related to the DNC levels in their unhatched eggs.

Absorption of NCZ varies among species (Yoder et al. 2005), and apparently pigeons do not absorb NCZ efficiently and therefore require greater dietary exposure to the chemical than do other species. Why pigeons respond differently from other species tested is not known. One possible explanation lies in the tendency of DNC particles to aggregate. When NCZ is ingested, it dissociates into its constituent parts, DNC and HDP. Once dissociated, however, DNC aggregates to form large particles that inhibit absorption through the intestinal wall (Rogers et al. 1983; Bynum et al. 2005; Yoder et al. 2006c). So if conditions in the pigeon gut promote aggregation of DNC, then it could require greater exposure to NCZ to achieve the same level of effectiveness as in other birds.

Regardless of the mechanism, failure to appreciate the low absorption efficiency in the feral pigeon has apparently resulted in test scenarios incorporating dietary NCZ levels $<80 \mathrm{mg}$ (kg body mass) $)^{-1}$ that are insufficient to inhibit reproduction reliably (Elder 1964; Giunchi et al. 2007). The lack of satisfactory results, in turn, has led to negative assessments regarding the potential usefulness of $\mathrm{NCZ}$ in pigeon population-control programs.

Initiation of replacement clutches was delayed by $\mathrm{NCZ}$ bait treatment. The physiological effects of $\mathrm{NCZ}$ on avian reproduction are various (Yoder et al. 2006a). The precise mechanism accounting for delayed initiation of a replacement clutch is not known, but it could involve antagonistic effects of NCZ on lipoprotein deposition, which, in turn, can decrease egg production (Yoder et al. 2006a).

Plasma DNC level varied considerably among female pigeons. We attribute this, in part, to the varying periods (31-49 days) that the birds were exposed to the treated bait. In other birds, plasma DNC levels do not stay constant during periods of exposure to NCZ, and we would expect the same type of response here (Primus et al. 2001; Johnston et al. 2002; Yoder et al. 2006b). The lack of a strong relationship between nestling productivity and female plasma DNC could be related to the timing of our blood sampling. We collected blood at the end of the treatment period, after the second egg was laid, whereas the critical period determining egg viability likely occurred within the hen weeks before. Plasma DNA can be used as a biomarker to detect exposure of pigeons to NCZ, but at this time it is unclear if it will be useful for determining the actual level of exposure.

NCZ produces temporary sterilisation. After a bird stops eating NCZ bait, the chemical clears from the blood within 4-6 days (Yoder et al. 2005). The temporary nature of NCZ's effect is both good and bad. It presents a challenge because the bait must be sufficiently appealing to induce pigeons to feed on it almost daily throughout the breeding season to maintain an effective blood titre. On the other hand, the temporary activity of $\mathrm{NCZ}$ is a benefit from the standpoint of non-target birds. Even if a non-target ingests enough bait to become reproductively inactive, the effect will not persist when the bird no longer consumes the bait. Bait placement is an effective means of reducing potential non-target exposure. For urban situations, application of NCZ bait on rooftops is an option. If pigeons can be induced to feed there, rooftops might be reasonably free from use by non-target birds and access could be rigidly controlled.

The fecundity of feral pigeons requires that a reproductive inhibitor be highly efficient and that its application be sustained. Using a simulation model, Giunchi et al. (2007) showed that $50 \%$ reduction in fertility can halve a pigeon population in 5 years. This seems to be a very substantial impact, particularly in that a pigeon population-management program is not likely to be conceived and carried out for only 5 years, nor is it likely to consist solely of contraception.

Reliance on a single method for reducing populations of feral pigeons will likely be unsuccessful. The more management tools that are available, the better the opportunity for the wildlife manager to devise a successful feral pigeon population-management plan. Effective integration of a reproductive inhibitor might first require lowering the existing population level through lethal control. Direct lethal control alone has repeatedly been ineffective in lowering population levels (Feare 2004). Mortality from control programs is readily balanced by increased recruitment within the population and immigration from other populations (Johnston and Janiga 1995). Whereas a reproductive inhibitor cannot alter immigration, it will suppress recruitment from within the population and thereby impede recovery of the population from the effects of lethal measures (Bomford 1990). Moreover, although difficult to achieve, restricting pigeons' access to food resources lowers carrying capacity and is a key component to successful population management (Haag-Wackernagel 1993; Feare 2004). If access to alternative food resources can be limited, pigeons will also be more likely to feed on the NCZ bait (Giunchi et al. 2007).

At the appropriate level of dietary exposure, we found $\mathrm{NCZ}$ to be a safe and effective reproductive inhibitor in feral pigeons. Despite lengthy periods of exposure, test subjects in this study survived and continued to reproduce after being taken off the treatment. To be sure, this is not a stand-alone solution for reducing overabundant pigeon populations. Instead, it represents a non-lethal option for long-term, integrated population management of an economically important invasive species. Successful use of NCZ for pigeon population control will depend on recognition of its strengths and limitations and the skill and commitment with which it is incorporated into integrated management efforts, particularly in urban and suburban settings.

\section{Acknowledgements}

Financial support for this study was provided by Innolytics, LLC. Erick Wolf and Alex MacDonald provided advice and technical assistance throughout the study. We thank Carol Furcolow and Marge Goodall at the National Wildlife Research Center in Ft Collins, CO, for analysing blood and egg samples. Assistance with animal care was provided by Eddie Bruce. Review comments provided by Dimitri Giunchi and three anonymous referees are very much appreciated. This research was carried out following animal welfare guidelines and standards of Good Laboratory Practices as specified in the approved USDA/NWRC study protocol QA-1329.

\section{References}

Andrews, E. J., Bennett, B. T., Clark, J. D., Houpt, K. A., Pasco, P. J., Robinson, G. W., and Boyce, J. R. (1993). Report of the AVMA panel on euthanasia. Journal of the American Veterinary Medical Association 202, 229-249. 
Avery, M. L., Keacher, K. L., and Tillman, E. A. (2006). Development of nicarbazin bait for managing rock pigeon (Columba livia) populations. Proceedings of the Vertebrate Pest Conference 23, 116-120.

Bennett, R. S., and Ganio, L. M. (1991). Overview of methods for evaluating effects of pesticides on reproduction in birds. EPA 600/3-91/048. US Environmental Protection Agency Environmental Research Laboratory, Corvallis, OR.

Bomford, M. (1990). role for fertility control in wildlife management? Bureau of Rural Resources, Bulletin No. 7. Canberra.

Bynum, K. S., Yoder, C. A., Eisemann, J. D., Johnston, J. J., and Miller, L. A. (2005). Development of nicarbazin as a reproductive inhibitor for resident Canada geese. Proceedings of the Wildlife Damage Management Conference 11, 179-189.

Bynum, K. S., Eisemann, J. D., Weaver, G. C., Yoder, C. A., Fagerstone, K. A., and Miller, L. A. (2007). Nicarbazin OvoControl G bait reduces hatchability of eggs laid by resident Canada geese in Oregon. Journal of Wildlife Management 71, 135-143. doi:10.2193/ 2005-603

Dolbeer, R. A. (1998). Population dynamics: the foundation of wildlife damage management for the 21 st century. Proceedings of the Vertebrate Pest Conference 18, 2-11.

Elder, W. H. (1964). Chemical inhibitors of ovulation in the pigeon. Journal of Wildlife Management 28, 556-575. doi:10.2307/3798209

Feare, C. J. (2004). Management of feral pigeon Columba livia populations: food is everything. In 'Advances in Vertebrate Pest Management, Vol. 3'. (Eds C. J. Feare and D. P. Cowan.) pp. 87-99. (Filander Verlag: Fürth.)

Giunchi, D., Baldaccini, N. E., Sbragia, G., and Soldatini, C. (2007). On the use of pharmacological sterilization to control feral pigeon populations. Wildlife Research 34, 306-318.

Haag-Wackernagel, D. (1993). Street pigeons in Basel. Nature 361, 200. doi:10.1038/361200a0

Haag-Wackernagel, D. (2006). Human disease caused by feral pigeons. In 'Advances in Vertebrate Pest Management'. (Eds C. J. Feare and D. P. Cowan.) pp. 31-58. (Filander Verlag: Fürth.)

Harris, A. D., Lautenbach, E., and Perencevich, E. (2005). A systematic review of quasi-experimental study designs in the fields of infection control and antibiotic resistance. Clinical Infectious Diseases 41, 77-82. doi: $10.1086 / 430713$

Johnston, J. J., Britton, W. M., Macdonald, A., Primus, T. M., Goodall, M. J., Yoder, C. A., Miller, L. A., and Fagerstone, K. A. (2002). Quantification of plasma and egg 4,4'-dinitrocarbanilide (DNC) residues for the efficient development of a nicarbazin-based contraceptive for pest waterfowl. Pest Management Science 58, 197-202. doi:10.1002/ps.439

Johnston, R. F. (1992). Rock dove. In 'The Birds of North America, No. 13'. (Eds A. Poole, P. Stettenheim, and F. Gill.) pp. 1-16. (The Academy of Natural Sciences: Philadelphia, \& The American Ornithologists' Union: Washington, DC.)
Johnston, R. F., and Janiga, M. (1995). 'Feral Pigeons.' (Oxford University Press: New York.)

Jones, J. E., Solisk, J., Hughes, B. L., Castaldo, D. J., and Toler, J. E. (1990). Production and egg quality responses of white leghorn layers to anticoccidial agents. Poultry Science 69, 378-387.

Langley, R. (1970). 'Practical Statistics Simply Explained.' (Dover Publications, Inc.: New York.)

Pimentel, D., Lach, L., Zuniga, R., and Morrison, D. (2000). Environmental and economic costs of nonindigenous species in the United States. Bioscience 50, 53-65. doi:10.1641/0006-3568(2000)050[0053: EAECON]2.3.CO;2

Primus, T. M., Kohler, D. J., Goodall, M. A., Yoder, C., Griggin, D., Miller, L., and Johnston, J. J. (2001). Determination of 4,4'-dinitrocarbanilide (DNC), the active component of the antifertility agent nicarbazin, in chicken, duck, and goose plasma. Journal of Agricultural and Food Chemistry 49, 3589-3593. doi:10.1021/jf0102463

Rogers, E. F., Brown, R. D., Brown, J. E., Kazazis, D. M., Leanza, W. J., Nichols, J. R., Ostlind, D. A., and Rodino, T. M. (1983). Nicarbazin complex yields dinitrocarbanilide as ultrafine crystals with improved anticoccidial activity. Science 222, 630-632. doi:10.1126/science. 6635662

Russell, W. M. S., and Burch, R. L. (1959). 'The Principles of Humane Experimental Technique.' (Methuen \& Co., Ltd: London.)

Sherwood, D. H., Milby, T. T., and Higgins, W. A. (1956). The effect of nicarbazin on reproduction in white rock breeder hens. Poultry Science 35, 1014-1019.

Smith, E. P. (2002). BACI design. In 'Encyclopedia of Environmetrics'. (Eds A. H. El-Shaarawi and W. W. Piegorsch.) pp. 141-148. (John Wiley \& Sons: Chichester.)

Yoder, C. A., Miller, L. A., and Bynum, K. S. (2005). Comparison of nicarbazin absorption in chickens, mallards, and Canada geese. Poultry Science 84, 1491-1494.

Yoder, C. A., Graham, J. K., and Miller, L. A. (2006a). Molecular effects of nicarbazin on avian reproduction. Poultry Science 85, 1285-1293.

Yoder, C. A., Graham, J. K., Miller, L. A., Bynum, K. S., Johnston, J. J., and Goodall, M. J. (2006b). Evaluation of nicarbazin as a potential waterfowl contraceptive using mallards as a model. Poultry Science $\mathbf{8 5}$, 1275-1284.

Yoder, C. A., Graham, J. K., Miller, L. A., Bynum, K. S., Johnston, J. J., and Goodall, M. J. (2006c). Effect of method of delivering nicarbazin to mallards on plasma 4,4'-dinitrocarbanilide levels and reproduction. Poultry Science 85, 1442-1448.

Manuscript received 9 February 2007, accepted 17 December 2007 